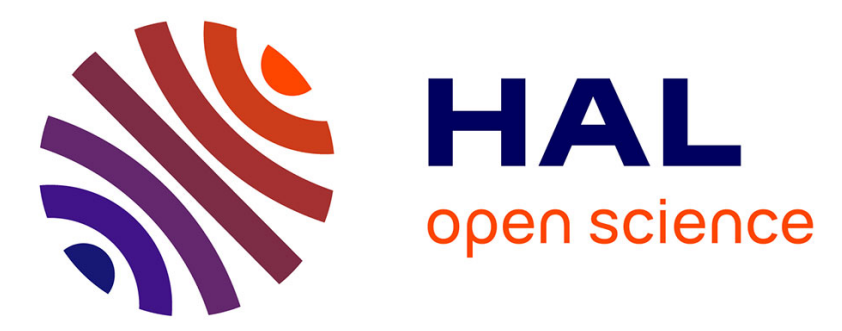

\title{
Cognitive function after adjuvant treatment for early breast cancer: a population-based longitudinal study
}

Jeanne Debess, Jens Østergaard Riis, Malene Cramer Engebjerg, Marianne Ewertz

\section{- To cite this version:}

Jeanne Debess, Jens Østergaard Riis, Malene Cramer Engebjerg, Marianne Ewertz. Cognitive function after adjuvant treatment for early breast cancer: a population-based longitudinal study. Breast Cancer Research and Treatment, 2010, 121 (1), pp.91-100. 10.1007/s10549-010-0756-8 . hal-00519326

\section{HAL Id: hal-00519326 \\ https://hal.science/hal-00519326}

Submitted on 20 Sep 2010

HAL is a multi-disciplinary open access archive for the deposit and dissemination of scientific research documents, whether they are published or not. The documents may come from teaching and research institutions in France or abroad, or from public or private research centers.
L'archive ouverte pluridisciplinaire $\mathbf{H A L}$, est destinée au dépôt et à la diffusion de documents scientifiques de niveau recherche, publiés ou non, émanant des établissements d'enseignement et de recherche français ou étrangers, des laboratoires publics ou privés. 
Cognitive function after adjuvant treatment for early breast cancer: A population-based longitudinal study

Jeanne Debess ${ }^{1}$, Jens $Ø$ stergaard Riis ${ }^{2}$, Malene Cramer Engebjerg ${ }^{3}$ and Marianne Ewertz ${ }^{4 *}$

${ }^{1}$ Department of Oncology, Aalborg Hospital, Aarhus University, Hobrovej 18-22, DK9000 Aalborg, Denmark (present address: University College of Northern Denmark, Selma Lagerløfs Vej 2 DK- 9220 Aalborg Ø)

2 Department of Neurology, Aalborg Hospital, Aarhus University, Hobrovej 18- 22, DK-9000 Aalborg, Denmark;

${ }^{3}$ Department of Clinical Epidemiology, Aarhus University Hospital, Olof Palmes Allé 43-45, 8200 Aarhus N, Denmark.

${ }^{4}$ Department of Oncology, Odense University Hospital, Institute of Clinical Research, University of Southern Denmark, Sdr. Boulevard 29, DK-5000 Odense C, Denmark;

*author for correspondence

Address for correspondence: Department of Oncology, Odense University Hospital, University of Southern Denmark, Sdr. Boulevard 29, DK-5000 Odense C, Denmark;

e-mail: mew@dadlnet.dk 


\section{Abstract}

Purpose. To examine cognitive function in patients with early breast cancer before and after adjuvant chemotherapy or six months of tamoxifen.

Methods. We performed a population-based study in the county of North Jutland, Denmark, including 120 women aged less than 60 years who received adjuvant chemotherapy with seven cycles of cyclophosphamide, epirubicin, and fluoruracil or adjuvant tamoxifen for six months for early breast cancer from 2004-2006. They were compared with an aged-matched group of 208 women without previous cancer selected randomly from the same population. Data were collected before start of adjuvant treatment and after six months by neuropsychological tests and questionnaires to evaluate cognitive function, quality of life, and psychological distress.

Results. Neuropsychological tests did not reveal any differences in cognitive function between breast cancer patients after chemotherapy and healthy controls. Patients rated their own cognitive functions as improved after six months, and patients, who did not receive adjuvant medical treatment, reached the same level as controls within 6 months. Patients receiving chemotherapy or tamoxifen were up to three times more likely than controls to rate themselves as impaired at six months.

Conclusion. Our results do not support that adjuvant chemotherapy is associated with cognitive side effects in breast cancer patients.

Keywords:Breast cancer, cognitive function, psychological distress, quality of life, population based longitudinal study. 


\section{Background}

Adjuvant chemotherapy with antracyclines and endocrine treatment with tamoxifen reduces the risk of dying from breast cancer (BC)[1] . Among side effects to adjuvant treatment, several studies have reported a decline in cognitive function like memory, attention, and executive function [2]. The first studies of cognitive function appeared around 1995 and showed from 28 to $75 \%$ impairment in cognitive function $[3,4]$.

However, these studies were small and cross-sectional. Later longitudinal studies including healthy controls and larger patient series have found either lower levels of impairment [5], no difference, or even improvement after chemotherapy [5,6]. Thus, the results are still at variance, probably due to differences in design and methodology [7,8]. An influence of tamoxifen on cognitive function has also been debated with one study showing no association [9] and others demonstrating impairment of memory and processing speed task $[10,11]$.

The purpose of this study was to examine cognitive function, psychological distress, and quality of life (QOL) before the initiation of adjuvant therapy for early BC and at completion of chemotherapy or after six months of tamoxifen compared with an agematched control group without prior cancer.

\section{Materials and methods}

\section{Study population}

We identified prospectively 196 women aged less than 60 years who had surgery for primary BC and no evidence of metastatic disease between May 1, 2004 and July 4, 2006. By use of the unique personal ID-numbers issued to all persons residing in Denmark, we were able to select a control group of 531 women who were age-matched to the study 
group from the entire female population of North Jutland Country. Among BC patients $124(63 \%)$ accepted to participate and among controls $224(42 \%)$ accepted. The selection process has been described in detail elsewhere [12]. Six months after baseline $120(61 \%)$ of the BC patients and 208 (39\%) of the controls remained in the study. Eligibility criteria for the $\mathrm{BC}$ patients and controls were: 1) no prior cancer 2) no diseases of the central nervous system; 3) no neurosurgery; 4) no neuropsychological testing within the last year; 5) no use of antidepressants or alcohol abuse; 6) no impairment of eye or hearing; 7) no illiteracy and not having Danish as mother tongue. Adjuvant treatment was given as follows: 75 patients $(62.5 \%)$ received CEF chemotherapy (cyclophosphamide $600 \mathrm{mg} / \mathrm{m}^{2}$ intravenously (IV), epirubicin $60 \mathrm{mg} / \mathrm{m}^{2} \mathrm{IV}$, and 5fluorouracil $600 \mathrm{mg} / \mathrm{m}^{2}$ IV every three weeks for seven cycles), and 26 (21.7\%) patients received tamoxifen $20 \mathrm{mg} /$ day while $19(15.8 \%)$ received no medical adjuvant treatment. One patient stopped chemotherapy after five cycles, and one patient had only one cycle followed by ovarian ablation but both stayed in the chemotherapy group for the analyses. Radiotherapy (RT) to the chest wall or residual breast with or without the regional lymph nodes was given to 79 patients $(66 \%)$ of whom $52(66 \%)$ were in the chemotherapy group, $17(21 \%)$ in the tamoxifen group and $10(13 \%)$ in the no medical treatment group. All BC patients receiving chemotherapy were offered standard antiemetic treatment. 


\section{Data collection}

At baseline (T1) after surgery but before initiation of any adjuvant treatment, data were collected regarding education, occupation, fertility, family history of BC, quality of life, and psychological distress using self-administered questionnaires filled in by the $\mathrm{BC}$ patients and controls at home. The questionnaires were checked for completeness by the research staff after the neuropsychological testing had been carried out. The second assessment (T2) was carried out four weeks after the last cycle of CEF or approximately six months after T1. Self-administered questionnaires regarding psychological distress and QOL were mailed to patients and controls and filled in at home before the neuropsychological testing. Data on adjuvant treatment derived from the medical records.

\section{Neuropsychological testing}

The neuropsychological status of all participants was assessed by the revised neurop sychological test-battery from the International Study of Postoperative Cognitive Dysfunction [13]. The ISPOCD test battery consists of four tests giving five test measures: 1) Visual Verbal Learning Test (VLT), 2) Concept Shifting Test (CST), 3) Stroop Colour Word Interference Test (SCWT), and 4) Letter-Digit Coding Test (LDCT). Testing was designed to encompass the following cognitive domains: concentration, episodic memory (intermediate and long-term memory), simple and complex attention, cognitive speed and flexibility, visual scanning, and executive function. Alternate forms of the tests were used in random order except for the STROOP test to minimise practise effects. General intelligence was evaluated using The Danish Adult Reading Test (DART) translated from the National Adult Reading 
Test (NART). This test was taken once at baseline. All tests were administered in the same quiet room and in a fixed order at the Department of Oncology by four trained research assistants [12].

\section{Rating scales and questionnaires}

To measure coping capacity we employed the Danish version of the 10-item scale General Perceived Self-Efficacy (GPS) [14]. We used the sum of the 10 items. A high validity and reliability has been documented in various populations [15]. Profile of Mood States (POMS) was administered to all participants to evaluate psychological distress. POMS measures six identifiable mood or affective states including five negative mood factors: tension-anxiety, depression-dejection, angerhostility, fatigue-inertia, confusion-bewilderment, and one positive mood factor, vigour [16].

Subjective cognitive functioning (SCF) was measured by four questions about memory, concentration/attention, mental burden, and vitality from the ISPOCD 2 study concerning change within the last four weeks [13]. The subjects rated themselves for each question on a 7-point scale ranging from (1) major improvement to (7) greatest decline regarding changes within the last month. In the analysis, scores from 1-3 were considered as improvement, 4 as no change, and 5-7 as impairment.

EORTC QLQ-C30 was used to measure quality of life. The questionnaire is translated into Danish and validated internationally by the EORTC Study Group [17]. It incorporates five functional scales (physical, role, cognitive, emotional, and social); three symptom scales (fatigue, pain, and nausea or vomiting); one global health scale, 
and six single items (dyspnoea, sleeplessness, loss of appetite, constipation, diarrhoea, and financialdifficulties) [18] and is used widely in Europe for cancer patients [19].

\section{Ethical considerations}

Oral and written information was given about the study. Those who accepted to participate gave informed consent before inclusion in the study. The study was approved by the Ethical Committee for Viborg and North Jutland Counties with reference number: VN 2004/15.

\section{Statistical methods}

\section{Study population}

Normal probability plots were used to assess the normal distribution of data. Measures of central tendency (mean, median) and dispersion ( $\mathrm{SD}$, interquartile range (IQR)) were computed initially for continuous variables and frequency counts and percentages for categorical variables. One-Way ANOVA was employed to explore differences between groups for selected variables.

\section{Neuropsychological test battery}

The control group was used to predict the difference in test scores between baseline and 6 months. This was achieved by fitting a linear regression model to the difference in test scores for the control group only. Because of a possible confounding effect on the neurop sychological tests, the difference was adjusted for baseline level of the test score, age, DART, educational level, length of retest interval, and difference in depression and 
tension between 6 months and baseline. Possible confounders were selected on the basis of theory found to influence test performance, e.g. depression [20], and kept in the model regardless of effects. The regression coefficients obtained from this model were then used to predict the expected differences in test scores for the breast cancer patients, divided into the three treatment groups. In this way, the use of a control group ensured that any practice effects between baseline and 6 months were controlled for. However, the differences in test scores in the control group were not normally distributed. Therefore, in order to classify the patients has having either declined or improved at 6 months we used the $5^{\text {th }}$ and $95^{\text {th }}$ percentiles of the residuals, i.e. the observed difference minus the predicted difference, from the control group to define $90 \%$ "distribution-free" prediction intervals. This is similar to the approach recommended by Temkin et al. [21]. Using these distribution-free prediction intervals the $\mathrm{BC}$ patients could be classified as either having improved, been stable or declined from baseline to 6 months. We also present results of binomial tests of the assumption of a five percent improvement and a five percent decline for the $\mathrm{BC}$ patients for each of the tests in the test battery. We finally calculated the percentage of $\mathrm{BC}$ patients who had declined or improved in two or more tests. Assuming that the individual tests in the test battery were independent and that there was no difference between the BC patients and the control group, $2.26 \%$ of the $\mathrm{BC}$ patients were expected to decline/improve in two or more tests. A binomial test of this assumption was calculated.

To control for type I error across the multiple outcome measures, a two-sided 0.005 critical level for a statistical significance was employed. A strict Bonferroni adjustment would be overly conservative due to correlations among outcomes measures [22]. 


\section{Psychological distress (POMS)}

For POMS, the approach was identical to the one described above for the neuropsychological test battery. The only difference was that the linear regression model fitting the difference in scores between baseline and 6 months for the control group was adjusted for baseline level, age, educational level, working status, smoking status, level of exercise, and self efficacy at baseline. Since the POMS consisted of six tests (compared with five tests in the test battery) we expected $3.28 \%$ of the BC patients to decline or improve in two or more tests under the assumption that there was no difference between the $\mathrm{BC}$ patients and the control group. Again the use of a control group to predict difference in scores ensured that any retest effects were taken properly care of.

\section{Quality of life}

Changes in QLQ-C30 from T1 to T2 were assessed by Wilcoxon sign rank test and the Kruskal Wallis one way ANOVA by ranks for differences between groups at T1 and T2 to account for the skewness in data distribution.

\section{Subjective cognitive functioning}

Proportions of patients impaired, unchanged or improved on subjective cognitive functioning (SCF) in each of the four study groups at $\mathrm{T} 1$ and $\mathrm{T} 2$ and the changes from T1 to T2 were compared by Fisher's exact test. Bivariate correlations using Spearman rank correlations were computed between the neuropsychological test scores and SCF questions. 
For all statistical analyses we used the statistical Package Stata version 9.2 for Windows and SAS software (version 9.1, SAS Institute Inc., Cary, NC).

\section{Results}

\section{Study population}

Table 1 shows the characteristics of the $120 \mathrm{BC}$ patients and 208 controls who completed all tests and questionnaires at $\mathrm{T} 1$ and $\mathrm{T} 2$. There were no significant differences between the patients and the controls with respect to DART, years in school and education. Patients receiving tamoxifen were significantly older than the patients in the other groups (tamoxifen group: mean 56.2; chemotherapy group: mean 47.2; no medical treatment group: mean 49.7; control group: mean 48.2). The time interval between the two neuropsychological assessments also differed, the interval being shortest for the chemotherapy group. Hence, all neuropsychological change analyses were adjusted for age and retest interval. Few patients in the chemotherapy group had completed radiotherapy at T2 whereas all in the tamoxifen group had. Similarly, none in the chemotherapy group had started endocrine treatment at $\mathrm{T} 2$, whereas the tamoxifen group had been treated for approximately six months. There were no significant differences in age or reason to refuse inclusion in the study between the included and excluded participants.

\section{Analyses of changes in scores on the neuropsychological test battery}

Between $\mathrm{T} 1$ and $\mathrm{T} 2$ no evident or consistent pattern of change in cognitive function was observed in the three groups of patients (Table 2). In the chemotherapy group $14.9 \%$ showed a decline on concept shifting test $(\mathrm{p}=0.002)$ but $12.2 \%$ showed a trend of improvement on delayed memory $(\mathrm{p}=0.023)$. The no medical treatment group was 
stable on most tests. In the tamoxifen group a trend of changes in both directions was seen as $19.2 \%$ declined on concept shifting test $(\mathrm{p}=0.017)$ and $19.2 \%$ improved on STROOP test $(\mathrm{p}=0.017)$.

Table 3 A shows that $15.4 \%$ in the Tamoxifen group declined on two or more tests $(\mathrm{p}=0.005)$. No other changes were found for any of the groups. Using the f-test, the baseline level, age, and intelligence most consistently predicted change from baseline to six month on most tests $(\mathrm{p}<0.001)$ (data not shown).

\section{Subjective cognitive functioning}

Table 4 illustrates the changes one month preceding $\mathrm{T} 1$ and one month preceding $\mathrm{T} 2$ in perceived cognitive function. Between $\mathrm{T} 1$ and $\mathrm{T} 2$ there were significant improvements in the perception of changes in all four cognitive functions in all patient groups, except for memory in the tamoxifen group. At T2, however, patients who had just completed chemotherapy still rated themselves as impaired with respect to cognitive abilities with relative risks (RRs) ranging from 1.2 to 2.8 compared with controls. Similarly, the RRs were between 1.2 and 2.8 in the tamoxifen group, i.e. these patients were still up to three times more likely to perceive themselves as impaired.

At baseline, BC patients who received no adjuvant medical treatment had as poor ratings as the patients who were later treated with chemotherapy or tamoxifen but at T2, this group had achieved almost similar ratings as the controls. As expected, the control group remained stable with similar ratings of subjective change at both $\mathrm{T} 1$ and $\mathrm{T} 2$. No significant correlations were found between the neuropsychological tests and the subjective ratings of cognitive functions (all $\mathrm{p}>0.05$ ). 
Psychological distress (POMS)

Between $\mathrm{T} 1$ and $\mathrm{T} 2$ patients treated with chemotherapy or tamoxifen improved significantly on the anger and tension dimensions. In the no treatment group there were significant improvements in fatigue and confusion (table 5). The number of patients showing improved mood scores on two or more scales was significantly higher than expected in all three groups, showing improvements from 16 to $32 \%$. (all $\mathrm{p}<0.0001$ ) (table 3 B). General Perceived Self-efficacy was stable over time and no differences were found between the groups (table 6).

\section{Quality of life}

Table 6 shows the symptom scores on EORTC QLQ-C30. All three groups of patients improved their role function $(\mathrm{p}<0.005)$. The chemotherapy group improved on emotional function but decreased in cognitive and physical function. The tamoxifen group had better scores on emotional function and global health $(\mathrm{p}<0.005)$ at $\mathrm{T} 2$. On the symptom scores, patients completing chemotherapy had higher scores on fatigue, nausea, dyspnoea, and appetite loss $(\mathrm{p} \leq 0.01)$ and all patients had significantly less pain. Compared with the control group the $\mathrm{BC}$ patients still scored lower at $\mathrm{T} 2$ on several functional scores (physical, role, cognitive, and social $(\mathrm{p}<0.005)$ and higher on symptom scores (fatigue, nausea, pain $(\mathrm{p}=0.02)$, dyspnoea, and sleeples sness $(\mathrm{p}<$ 0.005)). The distribution of data for most scores was skewed which explains why there could be a significant difference between two equal medians e.g. for fatigue in the tamoxifen group. 


\section{Discussion}

Previously we have reported that before start of adjuvant treatment, BC patients experienced a significant deterioration of their subjectively rated cognitive functioning, quality of life and of psychological well being but at the same time showed no impairment on the neurops ychological tests [12]. In this analysis, we have evaluated the same patients and controls six months later using the same questionnaires and neurop sychological test battery. While we no observed any major changes over time or between the chemotherapy and the no medical treatment groups on the neuropsychological test battery, all patients improved on most measures evaluating their subjectively rated level of cognitive and psychological distress. Patients who did not receive medical adjuvant treatment reached a level almost similar to that of the controls six months after surgery. Patients receiving chemotherapy or tamoxifen also improved but they still rated their cognitive functions as impaired compared with controls.

Our results do not provide evidence that chemotherapy with CEF is associated with cognitive side effects or so called "chemo brain". This is in agreement with other studies reporting that patients treated with standard dose CEF showed no impairment on test results $[5,6,23,24]$. Some studies have reported memory and concentration problems during or after treatment with chemotherapy [25-27] but few patients felt these problems had bothered them [28]. It is, however, difficult to make direct comparisons between the studies since the questionnaires as well as the treatment regimens varied. Treatments mostly consisted of CEF, docetaxel, cyclophosphamide, methotrexate, and 5-fluorouracil (CMF), adriamycin, cyclophosphamide (AC) and paclitaxel [6,23,25-27], followed by tamoxifen or aromatase inhibitors. Some gave no specific information 
about the cyctotoxic agents used [29]. A likely explanation of previous findings of cognitive impairment after adjuvant chemotherapy may be the lack of a matched control group and using a large number of cognitive tests [25] which may increase the chance of categorising a patient as impaired on one or more tests [30].

Among patients receiving tamoxifen $15.4 \%$ declined on two or more tests. This is in agreement with a cross-sectional study of patients who had impaired processing speed and memory after treatment with tamoxifen and / or anastrozole for a longer period $[10,11]$. Similarly, others have shown a decrease in cognitive function after six months in a prospective study [31] and one year after tamoxifen treatment in a randomised trial [32]. However, the most reliable predictors of change on the neurops ychological tests for all groups were baseline performance, intelligence and age which are well known to influence cognitive tests. Selection of these confounders made it possible to adjust the test results and thereby to predict a more valid change in cognitive function. Temkin et al. [21] have reported that baseline performance level accounted for up to $80 \%$ of the variance. We used the test battery from the ISPOCD study [33] because it has shown sensitivity to small and moderate postoperative cognitive decline in European patients and encompasses the same domains most often tested in "chemo brain" studies $[2,34]$. As in several other studies [35-37] we did not detect any association between neuropsychological test scores and subjective reports of cognitive function. Also, there were no associations between the changes in scores over six months. This discrepancy remains to be fully understood and clearly demands more attention [38] . However, self rating of cognitive capacity may not necessarily be related closely to objective measures, particularly when one is under the strain of a serious illness. 
In assessing psychological distress, we found improvements equivalent to those reported in other longitudinal studies $[39,40]$. In this analysis, we adjusted for several factors and the most reliable predictors of mood function at six months were baseline level and smoking. In a Danish nationwide cohort study [41], smoking was also reported to be associated with depressive symptoms. BC patients generally scored low on depression and anxiety with only $3.8 \%$ of the patients compared with $4.3 \%$ among controls scoring above threshold, using the POMS manual for cut off [16]. In our study population, fewer women were depressed than in the Danish nationwide cohort study where $13.7 \%$ of $\mathrm{BC}$ patients had a major depression three to four months after surgery [41]. This difference may be due either to the use of another questionnaire, the exclusion of major depressed participants, or to improvement during the additional three months after surgery. The ability to cope with life-situations did not change over time and was similar to the control group.

Receiving medical treatment had a negative influence on the QLQ - C30 symptom scores probably related to side effects from treatments [42]. Subjective ratings of memory and concentration abilities decreased after treatment with chemotherapy which is consistent with results from other studies with similarly treated BC patients $[26,43]$. $\mathrm{BC}$ patients treated with chemotherapy seemed to be more likely than controls to perceive themselves as impaired.

The well-being and Global Health scales improved over time even if it did not reach the same level as in the control group. This is consistent with other Scandinavian studies 
which also showed improvement over time after treatment. However, other studies showed lower levels of scores than in this study $[44,45]$. According to EORTC QLQC-30 norms for a Danish population-based study, the general level of functional scores in this study was higher and the symptom scores lower. [46].

The strength of our study design is that we included a control group from the same population which allowed us to estimate directly the level of symptoms to expect in women without cancer and to control for individual differences such as intelligence and education. Also, we performed a baseline assessment before start of treatment in order to be able to evaluate whether patients improved or declined, taking practise effects into account. Additionally, all patients received the same type of chemotherapy (CEF).We also included a small group of patients receiving no adjuvant medical treatment. An additional strength is the low attrition rate ranging from three percent among patients to seven percent among controls. Losses to follow-up are thus unlikely to explain the results. Furthermore, the regression-based approach is found to be the most sensitive in detecting cognitive changes and ens ures that a reliable and consistent decline in cognitive function would be found if present [47].

However, there are limitations to our study. The relatively low inclusion rate may have caused selection bias but neither patients nor controls declining to participate differed with respect to age and reasons for refusing from those included in the study and all four groups ended up being similar with respect to demographic factors. We therefore think that the participants at baseline were representative for the Danish population in general, i.e. that selection bias did not exert any great influence on the results. Dividing 
the patients by treatment, the groups became relatively small and the statistical power to detect small differences was reduced. Although we used well documented assessment tools we cannot rule out that these tools could not capture minute changes in cognitive function. During the data collection period, CEF was the standard chemotherapy. However, our study cannot address side effects of chemotherapy including the potentially neurotoxic taxans.

In conclusion, our results do not support that chemotherapy with CEF is associated with cognitive side effects. Patients who did not receive medical adjuvant treatment reached a subjective level almost similar to the controls six months after surgery.

\section{Acknowledgements}

This study was supported by the Danish Cancer Society. 
Reference List

1. EBCTCG (2005) Effects of chemotherapy and hormonal therapy for early breast cancer on recurrence and 15-year survival: an overview of the randomised trials. Lancet 365:1687-1717

2. Nelson CJ, Nandy N, Roth AJ (2007) Chemotherapy and cognitive deficits: mechanisms, findings, and potential interventions. Palliat Support Care 5:273-280

3. Schagen SB, van Dam FS, Muller MJ, et al (1999) Cognitive deficits after postoperative adjuvant chemotherapy for breast carcinoma. Cancer 85:640-650

4. Wieneke MH and Dienst E. (1995) Neuropsychological assessment of cognitive functioning following chemotherapy for breast cancer. Psychooncology 4:61-66

5. Schagen SB, Muller MJ, Boogerd W, et al (2006) Change in cognitive function after chemotherapy: a prospective longitudinal study in breast cancer patients. $J$ Natl Cancer Inst 98:1742-1745

6. Jenkins V, Shilling V, Deutsch G, et al(2006) A 3-year prospective study of the effects of adjuvant treatments on cognition in women with early stage breast cancer. Br J Cancer 94:828-834

7. Falleti MG, Sanfilippo A, Maruff P, et al (2005) The nature and severity of cognitive impairment associated with adjuvant chemotherapy in women with breast cancer: a meta-analysis of the current literature. Brain Cogn 59:60-70

8. Shilling V, Jenkins V, Trapala IS (2006) The (mis)classification of chemo-fog methodological inconsistencies in the investigation of cognitive impairment after chemotherapy. Breast Cancer Res Treat 95:125-129

9. Paganini-Hill A and Clark LJ (2000) Preliminary assessment of cognitive function in breast cancer patients treated with tamoxifen. Breast Cancer Res Treat 64:165176

10. Jenkins V, Shilling V, Fallowfield L, et al (2004) Does hormone therapy for the treatment of breast cancer have a detrimental effect on memory and cognition? A pilot study. Psychooncology 13:61-66

11. Palmer JL, Trotter T, Joy AA, et al (2008) Cognitive effects of Tamoxifen in premenopausal women with breast cancer compared to healthy controls. Journal of cancer survivorship: Research and practice 2:275-282

12. Debess J, Riis JØ RJ, Pedersen L, et al (2008) Cognitive function and quality of life after surgery for early breast cancer in North Jutland, Denmark. Acta Oncol 48:532-540

13. ISPOC (2006) International study on postoperative cognitive dysfunction. Available from: www.sps.ele.tue.nl/ispocd/index.html 
14. Schwarzer R. and Jerusalem M. (1995) Measures in health psychology: A user's portfolio. Causal and control beliefs. 1:35-37

15. Luszczynska A, Gutiérrez-Doña B,Schwarzer R (2005) General self-efficacy in various domains of human functioning: Evidence from five countries. International journal of psychology 40:80-89

16. McNair D M and Heuchert JW P (2003) Profile of Mood States Technical Updates. Multi-Health Systems Inc,New York

17. Aaronson NK, Ahmedzai S, Bergman B, et al (1993) The European Organization for Research and Treatment of Cancer QLQ-C30: a quality-of-life instrument for use in international clinical trials in oncology. J Natl Cancer Inst 85:365-376

18. Fayers PM, Aaronson NK, Bjordal K., et al (2001) The EORTC QLQ-C30 Scoring Manual. 3 rd ed. European Organisation for Research and Treatment of Cancer, Brussels;

19. Fayers P and Bottomley A (2002) The European Organization for Research and Treatment of Cancer QLQ-C30: a quality-of-life instrument for use in international clinical trials in oncology. Eur J Cancer 38 Suppl 4:S125-S133

20. Castaneda AE, Tuulio-Henriksson A, Marttunen M, et al (2008) A review on cognitive impairments in depressive and anxiety disorders with a focus on young adults. J Affect Disord 106:1-27

21. Temkin NR, Heaton RK, Grant I, et al (1999) Detecting significant change in neurop sychological test performance: a comparison of four models. J Int Neurops ychol Soc 5:357-369

22. Resnick SM, Maki PM, Rapp SR, et al (2006) Effects of combination estrogen plus progestin hormone treatment on cognition and affect. J Clin Endocrinol Metab 91:1802-1810

23. Hermelink K, Untch M, Lux MP, et al (2007) Cognitive function during neoadjuvant chemotherapy for breast cancer: results of a prospective, multicenter, longitudinal study. Cancer 109:1905-1913

24. Mehlsen M, Pedersen AD, Jensen AB, et al (2009) No indications of co gnitive side-effects in a prospective study of breast cancer patients receiving adjuvant chemotherapy. Psychooncology 18:248-57

25. Wefel JS, Lenzi R, Theriault RL, et al (2004) The cognitive sequelae of standarddose adjuvant chemotherapy in women with breast carcinoma: results of a prospective, randomized, longitudinal trial. Cancer 100:2292-2299

26. Bender CM, Sereika SM, Berga SL, et al (2006) Cognitive impairment associated with adjuvant therapy in breast cancer. Psychooncology 15:422-430 
27. Hurria A, Rosen C, Hud is C, et al (2006) Cognitive function of older patients receiving adjuvant chemotherapy for breast cancer: a pilot prospective longitudinal study. J Am Geriatr Soc 54:925-931

28. Shilling V and Jenkins V (2007) Self-reported cognitive problems in women receiving adjuvant therapy for breast cancer. Eur J Oncol Nurs 11:6-15

29. Servaes P, Verhagen CA,Bleijenberg G (2002) Relations between fatigue, neurop sychological functioning, and physical activity after treatment for breast carcinoma: daily self-report and objective behavior. Cancer $95: 2017-2026$

30. Dawson B and Trapp RG (2001) Basic \& Clinical Biostatistics. Third edition Lange Medical Books/McGraw-Hill Medical Publishing Division:

31. Collins B, Mackenzie J, Stewart A, et al (2009) Cognitive effects of hormonal therapy in early stage breast cancer patients: a prospective study. Psychooncology 18:811-821

32. Schilder CM, Eggens PC, Seynaeve C, et al(2009) Neuropsychological functioning in postmenopausal breast cancer patients treated with tamoxifen or exemestane after AC-chemotherapy: cross-sectional findings from the neurop sychological TEAM-side study. Acta Oncologica 48:76-85

33. Moller JT, Cluitmans P, Rasmussen LS, et al (1998) Long-term postoperative cognitive dysfunction in the elderly ISPOCD1 study. ISPOCD investigators. International Study of Post-Operative Cognitive Dysfunction. Lancet 351:857-861

34. Jansen CE, Miaskowski C, Dodd M, et al (2005) A metaanalysis of studies of the effects of cancer chemotherapy on various domains of cognitive function. Cancer 104:2222-2233

35. Castellon SA, Ganz PA, Bower JE, et al (2004) Neurocognitive performance in breast cancer survivors exposed to adjuvant chemotherapy and tamoxifen. J Clin Exp Neuropsychol 26:955-969

36. Stewart A, Collins B, Mackenzie J, et al (2008) The cognitive effects of adjuvant chemotherapy in early stage breast cancer: a prospective study. Psychooncology $17: 122-130$

37. van Dam FS, Schagen SB, Muller MJ, et al (1998) Impairment of cognitive function in women receiving adjuvant treatment for high-risk breast cancer: highdose versus standard-dose chemotherapy. J Natl Cancer Inst 90:210-218

38. Tannock IF, Ahles TA, Ganz PA, et al (2004) Cognitive impairment associated with chemotherapy for cancer: report of a workshop. J Clin Oncol 22 :2233-2239

39. Burgess C, Cornelius V, Love S, et al(2005) Depression and anxiety in women with early breast cancer: five year observational cohort study. BMJ 330:702 doi:10.1136/bmj.38343.670868.D3 
40. Mehnert A and Koch U (2007) Prevalence of acute and post-traumatic stress disorder and comorbid mental disorders in breast cancer patients during primary cancer care: a prospective study. Psychooncology 16:181-188

41. Christensen S, Zachariae R, Jensen AB, et al (2008) Prevalence and risk of depressive symptoms 3-4 months post-surgery in a nationwide cohort study of Danish women treated for early stage breast-cancer. Breast Cancer Res Treat 113:339-355

42. Shapiro CL and Recht A (2001) Side effects of adjuvant treatment of breast cancer. N Engl J Med 344:1997-2008

43. Browall M, Ahlberg K, Karlsson P, et al (2008) Health-related quality of life during adjuvant treatment for breast cancer among postmenopausal women. Eur $\mathrm{J}$ Oncol Nurs 12:180-189

44. Brandberg Y, Michelson H, Nilsson B, et al (2003) Quality of life in women with breast cancer during the first year after random assignment to adjuvant treatment with marrow-supported high-dose chemotherapy with cyclophosphamide, thiotepa, and carboplatin or tailored therapy with Fluorouracil, epirubicin, and cyclophosphamide: Scandinavian Breast Group Study 9401. J C lin Oncol 21:3659-3664

45. Schou I, Ekeberg O,Ruland CM (2005) The mediating role of appraisal and coping in the relationship between optimism-pessimism and quality of life. Psychooncology 14:718-727

46. Klee M, Groenvold M,Machin D (1997) Quality of life of Danish women: population-based norms of the EORTC QLQ-C30. Qual Life Res 6:27-34

47. Ouimet LA, Stewart A, Collins B, et al (2008) Measuring neurop sychological change following breast cancer treatment: An analysis of statistical models. J Clin Exp Neuropsychol 1-17

\begin{tabular}{|c|c|c|c|c|c|}
\hline Characte ristics & $\begin{array}{l}\text { Patients no } \\
\text { medical } \\
\text { treatment } \\
\mathrm{N}=19(\%)\end{array}$ & $\begin{array}{l}\text { Patients } \\
\text { chemothe rapy } \\
\mathrm{N}=75(\%)\end{array}$ & $\begin{array}{l}\text { Patients } \\
\text { tamoxifen } \\
N=26(\%)\end{array}$ & $\begin{array}{l}\text { Controls } \\
\mathbf{N}=\mathbf{2 0 8}(\%)\end{array}$ & p-value \\
\hline \multicolumn{6}{|l|}{ Age, years } \\
\hline Mean & 49.7 & 47.2 & 56.2 & 48.1 & \\
\hline Range & $39-59$ & $29-59$ & $44-59$ & $28-59$ & $<0.001$ \\
\hline \multicolumn{6}{|l|}{ Years in school } \\
\hline$<=9$ years & $4(21)$ & $8(11)$ & $9(35)$ & $44(21)$ & \\
\hline$>9$ years & $14(74)$ & $63(84)$ & $16(62)$ & 161 (77) & \\
\hline
\end{tabular}




\begin{tabular}{|c|c|c|c|c|c|}
\hline Other & $1(5.3)$ & $4(5.3)$ & $1(3.9)$ & $3(1.4)$ & 0.08 \\
\hline \multicolumn{6}{|l|}{ Education level } \\
\hline No education & $1(5.3)$ & $6(8.0)$ & $2(7.7)$ & $26(13)$ & \\
\hline$<3$ years & $11(58)$ & $33(44)$ & $15(58)$ & $93(45)$ & \\
\hline 3-4 years & $4(21)$ & $24(32)$ & $6(23)$ & $72(35)$ & \\
\hline$>4$ years & $2(11)$ & $7(9.3)$ & $2(7.7)$ & $8(3.9)$ & \\
\hline Other & $1(5.3)$ & $5(6.7)$ & $1(3.9)$ & $8(3.9)$ & 0.62 \\
\hline \multicolumn{6}{|l|}{ Menopausal s tatus } \\
\hline Pre/ perimenopausal & $11(58)$ & $57(76)$ & $2(7.7)$ & 134 (64) & \\
\hline Postmenopausal & $8(42)$ & $18(24)$ & $24(92)$ & $74(36)$ & $<0.001$ \\
\hline $\begin{array}{l}\text { Danish adult reading } \\
\text { test (baseline test) }\end{array}$ & $30.7(5.3)$ & $30.3(6.1)$ & $31.0(8.5)$ & $29.9(8.1)$ & 0.87 \\
\hline $\begin{array}{l}\text { Test interval T1 - T2 } \\
\text { Days (SD) }\end{array}$ & $183(14.6)$ & 167 (14.6) & $183(15.1)$ & $190(14.9)$ & $<0.001$ \\
\hline
\end{tabular}

Table 1 Characteristics of the study population

Table 2. Change in neuropsychological tests between baseline and after six months

\begin{tabular}{|c|c|c|c|c|c|c|c|c|}
\hline Test / group & $\begin{array}{l}\text { Number } \\
\text { of subjects }\end{array}$ & $\begin{array}{l}\% \\
\text { Improved }\end{array}$ & $\begin{array}{l}\text { CI: \% } \\
\text { improved }\end{array}$ & $\begin{array}{l}\text { Sign. level } \\
\text { improved }\end{array}$ & $\begin{array}{l}\% \\
\text { Stable }\end{array}$ & $\begin{array}{l}\% \\
\text { Declined }\end{array}$ & $\begin{array}{l}\text { CI: \% } \\
\text { declined }\end{array}$ & $\begin{array}{l}\text { Sign. } \\
\text { level } \\
\text { declined }\end{array}$ \\
\hline \multicolumn{2}{|c|}{ Visual verbal learning delayed } & & & & & & & \\
\hline Chemotherapy & 74 & 12.2 & $(5.7,21.8)$ & 0.023 & 83.8 & 4.1 & $(0.8,11.4)$ & 0.981 \\
\hline No treatment & 18 & 11.1 & $(1.4,34.7)$ & 0.453 & 77.8 & 11.1 & $(1.4,34.7)$ & 0.453 \\
\hline Tamoxifen & 26 & 3.8 & $(0.1,19.6)$ & 1.000 & 80.8 & 15.4 & $(4.4,34.9)$ & 0.078 \\
\hline \multicolumn{9}{|c|}{ Visual verbal learning total } \\
\hline Chemotherapy & 74 & 1.4 & $(0.0,7.3)$ & 0.220 & 94.6 & 4.1 & $(0.8,11.4)$ & 0.981 \\
\hline No treatment & 18 & & . & & 77.8 & 22.2 & $(6.4,47.6)$ & 0.022 \\
\hline Tamoxifen & 26 & 3.8 & $(0.1,19.6)$ & 1.000 & 80.8 & 15.4 & $(4.4,34.9)$ & 0.078 \\
\hline \multicolumn{9}{|c|}{ Concept shifting test } \\
\hline Chemotherapy & 74 & 2.7 & $(0.3,9.4)$ & 0.556 & 82.4 & 14.9 & $(7.7,25.0)$ & 0.002 \\
\hline No treatment & 18 & & . & & 94.4 & 5.6 & $(0.1,27.3)$ & 1.000 \\
\hline Tamoxifen & 26 & 11.5 & $(2.4,30.2)$ & 0.277 & 69.2 & 19.2 & $(6.6,39.4)$ & 0.017 \\
\hline \multicolumn{9}{|c|}{ S troop colour word test } \\
\hline Chemotherapy & 73 & 2.7 & $(0.3,9.5)$ & 0.573 & 90.4 & 6.8 & $(2.3,15.7)$ & 0.603 \\
\hline No treatment & 18 & & . & . & 94.4 & 5.6 & $(0.1,27.3)$ & 1.000 \\
\hline Tamoxifen & 26 & 19.2 & $(6.6,39.4)$ & 0.017 & 73.1 & 7.7 & $(0.9,25.1)$ & 0.752 \\
\hline \multicolumn{9}{|c|}{ Letter digit coding } \\
\hline Chemotherapy & 74 & 4.1 & $(0.8,11.4)$ & 0.981 & 86.9 & 9.5 & $(3.9,18.5)$ & 0.153 \\
\hline No treatment & 18 & 5.6 & $(0.1,27.3)$ & 1.000 & 94.4 & & & \\
\hline Tamoxifen & 26 & & . & & 92.3 & 7.7 & $(0.9,25.1)$ & 0.752 \\
\hline
\end{tabular}

The 5\% distribution-free prediction intervals used for the classification are adjusted for practice effects, baseline level, age, dart, educational level, retest interval and difference in depression and tension bet ween 6 months and baseline. 
Table 3. Number of patients with changes on more that two neuropsychological tests (A) and on more than two psychological distress scores (B) at six months.

\begin{tabular}{lllll}
\hline Perceived & Patients & Patients & Patients & Control \\
\hline
\end{tabular}

\begin{tabular}{|c|c|c|c|c|c|c|}
\hline \multirow{3}{*}{$\begin{array}{l}\text { A: Test battery* } \\
\text { Declined on } \geq 2 \text { tests } \\
\text { Improved on } \geq 2 \text { tests }\end{array}$} & $\begin{array}{c}\text { Chemo- } \\
\text { the rapy } \\
\mathrm{N}=73\end{array}$ & $\begin{array}{l}\text { Sign. } \\
\text { level }\end{array}$ & $\begin{array}{c}\text { Tamoxifen } \\
\mathrm{N}=26\end{array}$ & $\begin{array}{l}\text { Sign. } \\
\text { le vel }\end{array}$ & $\begin{array}{c}\text { No me dical } \\
\text { tre atment } \\
\mathrm{N}=18\end{array}$ & $\begin{array}{l}\text { Sign. } \\
\text { le vel }\end{array}$ \\
\hline & $4.1 \%$ & 0.457 & $15.4 \%$ & 0.005 & $11.1 \%$ & 0.123 \\
\hline & $2.7 \%$ & 0.986 & $7.7 \%$ & 0.232 &. & \\
\hline \multirow{3}{*}{$\begin{array}{l}\text { B : POMS** } \\
\text { Declined on } \geq 2 \text { mood } \\
\text { functions } \\
\text { Improved on } \geq 2 \operatorname{mood} \\
\text { functions }\end{array}$} & $\mathrm{N}=75$ & & $\mathrm{~N}=26$ & & $\mathrm{~N}=19$ & \\
\hline & $6.7 \%$ & 0.200 &., & & $5.3 \%$ & 0.938 \\
\hline & $16.0 \%$ & $<0.0001$ & $30.8 \%$ & $<0.0001$ & $31.6 \%$ & $<0.0001$ \\
\hline
\end{tabular}

*Expected percentage declined/ improved on tests: 2.26 based on the control group.

**Expected percentage declined/ improved on POMS: 3.28 based on the control group.

Table 4. Change in subjective cognitive function between baseline (T1) and six months (T2) 


\begin{tabular}{|c|c|c|c|c|c|c|c|c|}
\hline \multirow{2}{*}{$\begin{array}{l}\text { cognitive function } \\
\text { Memory }\end{array}$} & \multicolumn{2}{|c|}{$\begin{array}{c}\text { No treatment } \\
N=19(\%)\end{array}$} & \multicolumn{2}{|c|}{$\begin{array}{c}\text { Chemotherapy } \\
\mathrm{N}=75(\%)\end{array}$} & \multicolumn{2}{|c|}{$\begin{array}{l}\text { tamoxifen } \\
\mathrm{N}=26(\%)\end{array}$} & \multicolumn{2}{|c|}{$\begin{array}{c}\text { group } \\
\mathbf{N}=\mathbf{2 0 8}(\%)\end{array}$} \\
\hline & T1 & $\mathbf{T 2}$ & T1 & $\mathbf{T} 2$ & T1 & $\mathbf{T 2}$ & T1 & T2 \\
\hline Impairment & $11(58)$ & $3(16)$ & $28(37)$ & $22(29)$ & $12(46)$ & $8(31)$ & $22(11)$ & $24(12)$ \\
\hline No change & $6(32)$ & $12(63)$ & $45(60)$ & $42(56)$ & $14(54)$ & $17(65)$ & $174(84)$ & $172(83)$ \\
\hline Improvement & $2(10)$ & $4(21)^{*}$ & $2(2.7)$ & $11(14)^{*}$ & $0(0.0)$ & $1(4.0)$ & $12(5.8)$ & $12(5.8)$ \\
\hline Concentration & & & & & & & & \\
\hline Impairment & $11(58)$ & $3(16)$ & $33(44)$ & $10(13)$ & $17(65)$ & $9(35)$ & 24 (12) & $24(12)$ \\
\hline No change & $6(32)$ & $12(63)$ & $41(55)$ & $57(76)$ & $9(35)$ & $17(65)$ & $173(83)$ & $172(83)$ \\
\hline $\begin{array}{l}\text { Improvement } \\
\text { Mental fatigue }\end{array}$ & $2(10)$ & $4(21)^{*}$ & $1(1.3)$ & $8(11) \mathfrak{a}$ & $0(0.0)$ & $0(0.0)^{*}$ & $11(5.3)$ & $12(5.8)$ \\
\hline Impairment & $12(63)$ & $4(21)$ & $40(53)$ & $25(33)$ & $19(73)$ & $8(31)$ & $19(9.1)$ & $28(14)$ \\
\hline No change & $4(21)$ & $10(53)$ & $34(45)$ & $36(48)$ & 7 (27) & $17(65)$ & $179(86)$ & $166(80)$ \\
\hline $\begin{array}{l}\text { Improvement } \\
\text { Vigor }\end{array}$ & $3(16)$ & $5(26)^{*}$ & $1(1.3)$ & $14(19) \S$ & $0(0.0)$ & $1(4.0) \#$ & $10(4.8)$ & $14(6.3)$ \\
\hline Impairment & $13(68)$ & $3(16)$ & $41(55)$ & $32(43)$ & $20(77)$ & $6(23)$ & $41(20)$ & $42(20)$ \\
\hline No change & $4(21)$ & $10(63)$ & $27(36)$ & $23(31)$ & $3(12)$ & $15(58)$ & $144(69)$ & $135(65)$ \\
\hline Improvement & $2(11)$ & $6(31) \S$ & $7(9.3)$ & $20(27)^{*}$ & $3(12)$ & $5(19) \mathfrak{a}$ & $23(11)$ & $31(15)$ \\
\hline
\end{tabular}

Fischer exact test: baseline versus 6 month for each study group and cognitive function *: $\mathrm{p}<0.05$; \#: $\mathrm{p}<0.01 ; \S: \mathrm{p}<0.005 ;$ a $\mathrm{p}<0.001$

Table5. Change in psychological distress (POMS) between baseline and six months.

\begin{tabular}{|c|c|c|c|c|c|c|c|c|}
\hline Test / Group & $\begin{array}{l}\text { Number of } \\
\text { Subjects }\end{array}$ & $\begin{array}{l}\% \\
\text { Improved }\end{array}$ & $\begin{array}{l}\text { CI: \% } \\
\text { Improved }\end{array}$ & $\begin{array}{l}\text { Sign. Level } \\
\text { Improved }\end{array}$ & $\begin{array}{l}\% \\
\text { Stable }\end{array}$ & $\begin{array}{l}\% \\
\text { Declined }\end{array}$ & $\begin{array}{l}\text { CI: \% } \\
\text { Declined }\end{array}$ & $\begin{array}{l}\text { Sign. level } \\
\text { Declined }\end{array}$ \\
\hline \multicolumn{9}{|l|}{ Anger } \\
\hline Chemotherapy & 75 & 13.3 & $(6.6,23.2)$ & 0.008 & 80.0 & 6.7 & $(2.2,14.9)$ & 0.642 \\
\hline No treatment & 19 & 15.8 & $(3.4,39.6)$ & 0.133 & 84.2 & & . & \\
\hline Tamoxifen & 26 & 23.1 & $(9.0,43.6)$ & 0.003 & 76.9 & & . & \\
\hline \multicolumn{9}{|l|}{ Depression } \\
\hline Chemotherapy & 75 & 10.7 & $(4.7,19.9)$ & 0.067 & 85.3 & 4.0 & $(0.8,11.2)$ & 0.960 \\
\hline No treatment & 19 & 21.1 & $(6.1,45.6)$ & 0.027 & 73.7 & 5.3 & $(0.1,26.0)$ & 1.000 \\
\hline Tamoxifen & 26 & 15.4 & $(4.4,34.9)$ & 0.078 & 84.6 & & & \\
\hline \multicolumn{9}{|l|}{ Tension } \\
\hline Chemotherapy & 75 & 16.0 & $(8.6,26.3)$ & 0.001 & 81.3 & 2.7 & $(0.3,9.3)$ & 0.539 \\
\hline No treatment & 19 & 21.1 & $(6.1,45.6)$ & 0.027 & 73.7 & 5.3 & $(0.1,26.0)$ & 1.000 \\
\hline Tamoxifen & 26 & 34.6 & $(17.2,55.7)$ & $<0.0001$ & 65.4 & & & \\
\hline \multicolumn{9}{|l|}{ Vigor } \\
\hline Chemotherapy & 75 & 2.7 & $(0.3,9.3)$ & 0.539 & 86.7 & 10.7 & $(4.7,19.9)$ & 0.067 \\
\hline No treatment & 19 & 15.8 & $(3.4,39.6)$ & 0.133 & 78.9 & 5.3 & $(0.1,26.0)$ & 1.000 \\
\hline
\end{tabular}


Debess et al.

Cognitive function and breast cancer

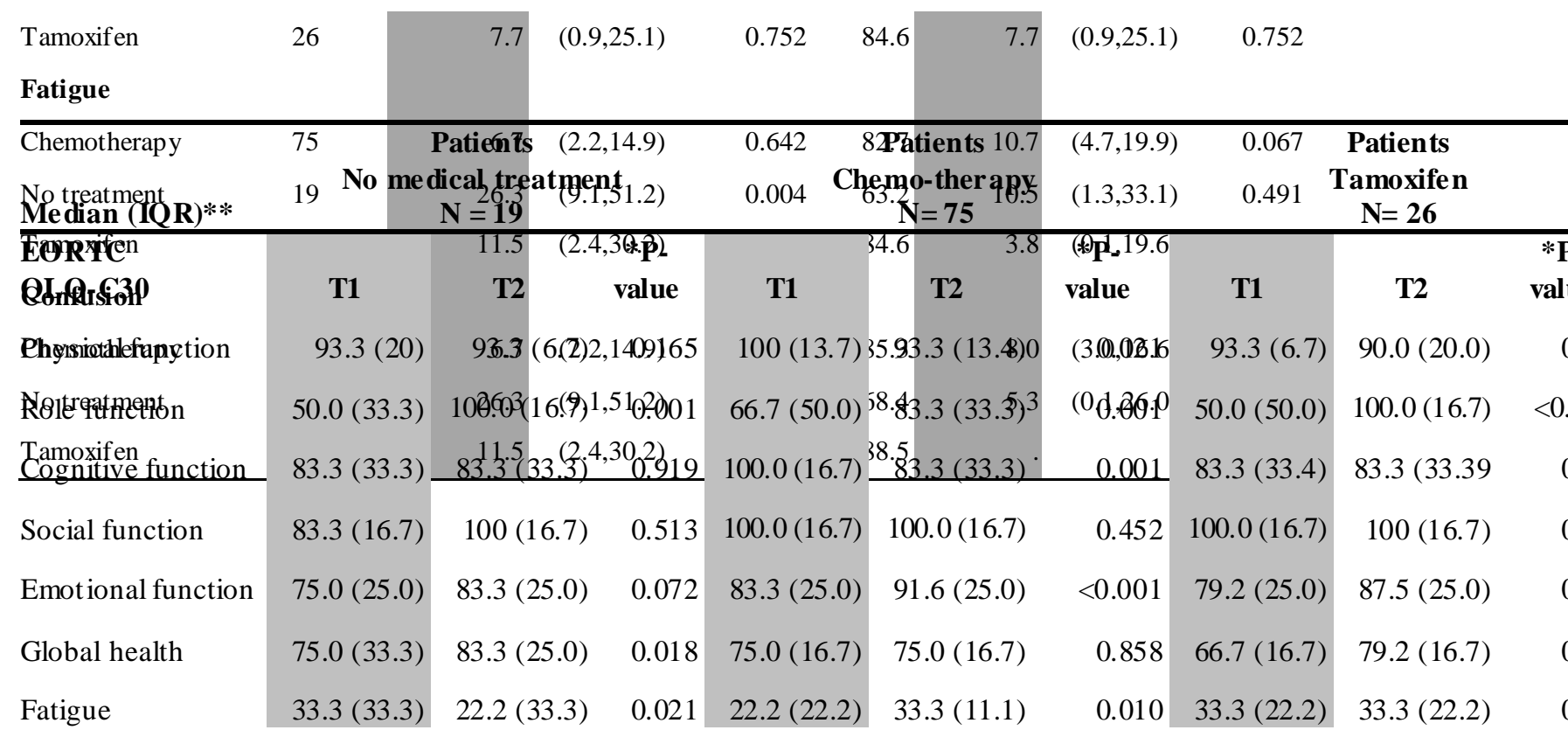

The $5 \%$ distribution-free prediction intervals used for the classification are adjusted for retest effect, baseline level, age, educational level, working status, smoking status, level of exercise and self-efficacy at baseline. 
Debess et al.

Cognitive function and breast cancer

\begin{tabular}{lrrrrrrrr|r} 
Nausea/Vo mit ing & $0.0(0.0)$ & $0.0(0.0)$ & 0.317 & $0.0(0.0)$ & $0.0(16.6)$ & 0.002 & $0.0(0.0)$ & $0.0(0.0)$ \\
Sleeplessness & $33.3(33.3)$ & $33.3(33.3)$ & 0.639 & $0.0(33.3)$ & $33.3(33.3)$ & 0.042 & $33.3(33.3)$ & $16.7(66.7)$ \\
Pain & $33.3(16.7)$ & $16.6(16.7)$ & 0.006 & $16.7(33.3)$ & $0.0(16.7)$ & $<0.001$ & $33.3(33.3)$ & $25.0(33.0)$ \\
Dyspnoea & $0.0(0.0)$ & $0.0(0.0)$ & 0.564 & $0.0(0.0)$ & $0.0(33.3)$ & $<0.001$ & $0.0(0.0)$ & $0.0(0.0)$ \\
Appetite loss & $0.0(33.3)$ & $0.0(0.0)$ & 0.180 & $0.0(0.0)$ & $0.0(0.0)$ & 0.014 & $0.0(33.3)$ & $0.0(0.0)$ \\
\hline $\begin{array}{l}\text { General Percei ved } \\
\text { self-efficacy }\end{array}$ & & $\mathbf{N}=\mathbf{1 9}$ & & & $\mathbf{N}=\mathbf{7 5}$ & & & $\mathbf{N}=\mathbf{2 5}$ \\
Mean; (SD) & $30.4(5.4)$ & $28.8(5.3)$ & 0.126 & $31.9(5.1)$ & $31.5(5.0)$ & 0.451 & $30.8(6.3)$ & $30.1(4.8)$
\end{tabular}

Table 6.EORTC QLQ C-30 scores at baseline (T1) and six months (T2)

**(IQR): Interquartile Range. * P-values: change fro $\mathrm{m}$ baseline $\mathrm{T} 1$ to six month $\mathrm{T} 2$ for each score and groups. 